\title{
O racismo na/da política proibicionista brasileira: redução de danos como antídoto antirracista*
}

\author{
Brazilian prohibitionist policy's racism: harm reduction \\ as an anti-racist antidote
}

Lucia Cristina dos Santos Rosa**

Thaís de Andrade Alves Guimarães***

\begin{abstract}
Resumo - Neste ensaio, objetiva-se analisar o racismo constitutivo na e da política proibicionista brasileira sobre drogas, apresentando os elementos que a configuram como uma política racializada e interseccionada. Na perspectiva de enfrentamento desse quadro, é apresentada a redução de danos como antídoto antirracista.

Palavras-chave: proibicionismo; redução de danos; políticas de drogas; racismo; antirracismo.
\end{abstract}

\begin{abstract}
This essay aims to analyze the inborn racism in and of the Brazilian prohibitionist drug policy, presenting the elements that characterize it as a racialized and intersected policy. In the perspective of confronting this picture of intrinsic racism, harm reduction is presented as an anti-racism antidote.

Keywords: prohibitionist; harm reduction; drugs policy; racism; anti-racism.
\end{abstract}

\footnotetext{
* O presente trabalho foi realizado com apoio da Fundação de Amparo à Pesquisa do Estado do Piauí (FAPEPI) e da Coordenação de Aperfeiçoamento de Pessoal de Nível Superior - Brasil (CAPES) - Código de Financiamento 001.

** Professora Titular do Departamento de Serviço Social e do Programa de Pós-Graduação em Políticas Públicas da Universidade Federal do Piauí (UFPI). Assistente Social. Pós-Doutora em Saúde Coletiva pela Universidade Estadual de Campinas (UNICAMP); Doutora em Serviço Social pela Universidade Federal do Rio de Janeiro (UFRJ) e Doutora em Sociologia pela Universidade Federal de Pernambuco (UFPE). Bolsista de Produtividade em Pesquisa nível 2 (PQ2) do CNPQ. E-mail: luciacsrosa@gmail.com. ORCID: https://orcid.org/0000-00032612-2981.

*** Assistente Social da Universidade Federal do Oeste da Bahia (UFOB); Doutoranda em Políticas Públicas pela Universidade Federal do Piauí (UFPI); Mestra em Prevenção e Assistência a Usuários de Álcool e Outras Drogas pelo Hospital de Clínicas de Porto Alegre/Universidade Federal do Rio Grande do Sul (HCPA/UFRGS). E-mail: thais.hcpa.ufrgs@gmail.com. ORCID: https://orcid.org/0000-0002-3667-1813.
} 


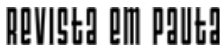

\} O RACISMO NA/DA POLÍTICA PROIBICIONISTA - ROSA, L. C. S.; GUIMARÃES, T. A. A. \}

DOI: $10.12957 /$ REP.2020.47204

\section{Introdução}

O Brasil se constitui historicamente, no cerne dos países capitalistas ocidentais, como uma sociedade periférica. Em meio a uma profunda desigualdade estrutural, condicionada por marcadores de classe, raça e gênero, baseada na colonialidade, tal sociedade delineia "um padrão de poder que articula diversas dimensões da existência social. Trabalho, subjetividade, autoridade, sexualidade, cultura, identidade, [...] dimensões constituintes das experiências sociais de indivíduos e grupos" (SANTOS, 2012, p. 40). Desse modo, essa sociedade se configurou a partir da colonização pelo europeu, homem e branco, sendo uma colônia de exploração, em que a metrópole extraía toda a riqueza local para seu benefício exclusivo. As relações de trabalho que se constroem têm por base o trabalho escravo do indígena e do negro, sequestrado da África.

Neste país, as desigualdades foram naturalizadas pelas elites dominantes, o que influencia como uma marca histórica na construção do éthos do brasileiro e, consequentemente, da esfera pública no país, território onde se forja e se condensa a opinião pública, sobretudo em termos do reconhecimento da alteridade e dos direitos do outro, o que estrutura as relações sociais. Como afirmam Marx e Engels (2001, p. 83), as "ideias dominantes de uma época nunca passaram das ideias das classes dominantes", pois a dominação não ocorre apenas na esfera econômica, nem exclusivamente pela força, mas no plano das ideias, da busca do consenso, materializandose nas ações estatais, embora persistindo no jogo das disputas políticas e sociais.

A Independência do Brasil, em 1822, a Libertação dos Escravos, em 1888, e a instituição da República, em 1889, pouco alteraram o padrão das relações sociais no Brasil, configurando meramente arranjos entre as elites dominantes. Os modelos dominantes se impuseram em todas as esferas na sociedade brasileira contra os interesses dos segmentos dominados (LEAL, 2012). Isso se dá, sobretudo, a partir da associação do binômio repressãoassistencialismo (IAMAMOTO; CARVALHO, 2011), materializado na cultura do favor e da gratidão, permeado pela violência dirigida aos "de baixo", ou seja, aos que foram excluídos das decisões políticas e dos benefícios sociais.

Nesse cenário, o negro liberto, sem política que o integrasse a uma sociedade em acelerado processo de urbanização e industrialização, vai ocupar as áreas de morros, favelas e ruas, resistindo aos processos de intensificação das desigualdades sociais. Por sua vez, os governantes, no afã de acelerar a industrialização, vão implementar uma política de estimulo à migração europeia, que é associada a uma política de embranquecimento da população brasileira, posto que os negros passam a ser responsabilizados pelas mazelas sociais do país (COSTA, 1983). Tal violência simbólica é reforçada pelas ideias de que haveria no Brasil uma "democracia racial" (FREI$R E, 1996)$ que camufla as questões raciais sob o manto de uma relação inte- 


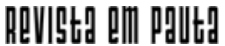

\} O RACISMO NA/DA POLITICA PROIBICIONISTA - ROSA, L. C. S.; GUIMARÃES, T. A. A. \}

DOI: $10.12957 /$ REP.2020.47204

rétnica harmoniosa e pacífica, posta como subjacente. Além disso, de que haveria uma relação cordata entre brancos e negros no país, o que o movimento negro vem desmistificando.

Nessa perspectiva, as primeiras medidas públicas para responder às manifestações da questão social emergente concatenaram: medidas saneadoras do meio urbano, sintetizadas no higienismo; fomento às ações benemerentes, que associam "ajuda" ao favor, materializado no assistencialismo e institucionalização, na segregação, via internação, no geral forçada, dos segmentos tornados "indesejáveis" socialmente.

Assim, o principal "beneficiário" da ação governamental era a população negra, o que fica evidente nas primeiras ações de combate às "drogas" no país, imbricadamente articuladas à segurança pública. Ademais, possuem marca da regulação via princípios de hierarquização social, por meio da concentração de ação em áreas duras, "aquelas nas quais a dimensão racial importa, e onde normalmente isto pende de maneira negativa para negros" (SANTOS, 2012, p. 42). O sistema jurídico e todo o aparato repressivo-punitivo, incluindo o sistema penitenciário, configuraram uma política criminal em relação ao consumo de substâncias psicoativas (SPAs), em que imperou a seletividade penal.

Nesse arcabouço, torna-se indefensável o princípio liberal de que todos "são iguais perante a lei". Logo, o direito positivo é maculado, existindo racismo sobretudo na forma de implementar a política sobre drogas no país, segundo Monsma (2013), a partir de dupla dimensão: (1) dominação étnica, de um grupo que se sente superior e que domina outros; e (2) dominação ideológica, ao essencializar negativamente o grupo subordinado.

Na década de 1930, o Brasil ingressa no processo acelerado de modernização, ocasionando mudanças nas elites dominantes com a "revolução pelo alto" (VIANA, 1983). A partir disso, as manifestações da questão social tornam-se caso de política, erigindo todo o sistema de proteção social do país, fundado em um sistema de proteção social meritocrático e particularista (DRAIBE, 1989). Este, por sua vez, inaugura a cidadania regulada (SANTOS, 1987), voltada para uma parcela ínfima da população brasileira, o trabalhador urbano, com oficio reconhecido. Tal estrutura processa uma cisão entre o trabalhador e o pobre, a partir da política social. Ou seja, a própria ação estatal recria desigualdades sociais (TELLES, 1999) ao restringir direitos e fazer a distinção entre segmentos que "vivem do trabalho" (ANTUNES, 1998).

Logo, as desigualdades sociais no Brasil se reproduziram nas políticas sociais, conjugadas a todo o contexto ditatorial que predominou em suas origens e desenvolvimento, em meio à construção de uma esfera de disputa de projetos e modelos de trato da questão social para o país. Dessa forma, as políticas sobre drogas no Brasil, desde suas origens, interseccionaram as dimensões de classe social, gênero e étnico-raciais, com direção bem delineada da elite masculina branca contra os homens pobres e negros. 


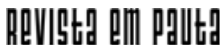

\} O RACISMO NA/DA POLÍTICA PROIBICIONISTA - ROSA, L. C. S.; GUIMARÃES, T. A. A. \}

DOI: $10.12957 /$ REP.2020.47204

No período da Ditadura Militar de 1964, a população indígena se torna, também, alvo da política de segurança nacional no cerne da "guerra às drogas". Tal política evidencia-se na "Operação Maconha", de 1978, como uma explícita guerra que confronta dois universos culturais distintos, do aparato branco contra os índios Guajajara. Por meio de campanhas inspiradas em marcadores racistas, observa-se uma "clara vontade etnocida por parte da nossa civilização, que busca denegrir e suprimir aspectos considerados indesejáveis na cultura dos remanescentes indígenas no Brasil" (HENMAN, 2016, p. 320). Há, também, contraposição à legislação de então, que protegia os costumes indígenas em relação ao consumo da maconha, inserido em práticas rituais e sob controle cultural.

Paulatinamente, ocorrem as disputas em torno dos variados sentidos e usos das SPAs, inclusive inseridos no narcotráfico, como via de trabalho informal para um número significativo de jovens, pobres e negros, das periferias brasileiras, enquadrados como traficantes. Deste modo, as diferenças raciais, associadas às condições socioeconômicas precárias e aos valores culturais contra-hegemônicos, comumente vulnerabilizam determinados segmentos que têm as piores posições na hierarquia social. Como afirma Barata (2009, p. 56), "qualquer consideração das desigualdades sociais em relação a grupos étnicos carrega a dupla determinação: a posição social que tais grupos ocupam na sociedade e a aceitação/rechaço que possam ter frente aos grupos majoritários".

A política de saúde mental, álcool e outras drogas reproduziu o mesmo padrão, pois todo o modelo manicomial foi erigido para responder às questões sociais trazidas pelos loucos pobres (RESENDE, 1990), muitos dos quais não brancos, como informam Conceição, Nery e Pinho (2002). Logo, o acesso e usufruto de direitos sociais são socialmente determinados. Historicamente, a política de saúde se conformou com um duplo padrão de organização; de um lado, para atender ao trabalhador segurado do sistema previdenciário. De outro, para atender ao pobre, via Ministério da Saúde, oferecendo, no geral, um serviço de baixa qualidade, reforçando as iniquidades sociais.

Com a redemocratização da sociedade brasileira e fruto das lutas sociais, a Constituição Federal de 1988 produz uma ruptura na política de saúde ao afirmar, em seu art. 196, que "saúde é direito de todos e dever do Estado". Ao institucionalizar o Sistema Único de Saúde (SUS) na Seguridade Social, postulando a universalidade do direito, ocorre a ampliação da cidadania no plano legal/constitucional, que abarca a todos indistintamente. Nessa nova configuração histórica, novos modelos e novas perspectivas de compreender o consumo e os consumidores de SPA emergem, tendo por paradigma a redução de danos, fundamentada nos direitos humanos, o que tensiona a concepção proibicionista dominante.

Objetiva-se, por meio deste artigo, analisar o racismo constitutivo na e da política proibicionista, que vem orientando as ações sobre drogas 


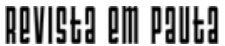

\} O RACISMO NA/DA POLÍTICA PROIBICIONISTA - ROSA, L. C. S.; GUIMARÃES, T. A. A. \}

DOI: $10.12957 /$ REP.2020.47204

no Brasil. Além disso, busca sinalizar o paradigma da redução de danos como antídoto antirracista, por sua relação imbricada com os direitos humanos e a equidade, através da crescente preocupação da configuração assistencial em se moldar às necessidades culturais e sociais dos usuários.

Sem a pretensão de exaurir a discussão, busca-se trazer elementos para o debate em um contexto de intensos acirramentos, na perspectiva de desmonte do SUS e tendência de remanicomialização da política de saúde mental, álcool e outras drogas, que desconsidera a complexidade e multiculturalidade da sociedade brasileira.

\section{A política de drogas proibicionista: uma questão de classe, cor e endereço}

Os registros históricos informam que as SPAs sempre estiveram presentes no percurso do ser humano, com uso socialmente determinado a partir de diversos valores e significados. Foram utilizadas com várias finalidades, destacadamente para uso medicinal, tais como aliviar a dor e curar enfermidades; para uso lúdico, recreativo, em datas celebrativas; e para possibilitar autoconhecimento ou a transcendência em rituais religiosos.

Atualmente, também têm propósito financeiro, tanto para enriquecimento ilícito, via narcotráfico, quanto para fomentar o trabalho informal de "aviões". Em diferentes tempos e lugares, o consumo de psicoativos teve distintas finalidades e funções. Para Nery Filho (2012, p. 18), "os humanos usam drogas porque se tornaram humanos"; ou seja, fazem parte da condição humana a própria criação e reinvenção de si, a partir da capacidade de os seres humanos simbolizarem e tomarem ciência de si ao saberem de sua finitude.

A partir da intensificação da industrialização, com o aceleramento do processo de urbanização, o desenvolvimento da medicina moderna (avanço dos diagnósticos e da farmacologia), bem como o avanço do Estado por meio de seu aparato jurídico e policial, governos e medicina, passam a constituir instância de controle da produção, distribuição e consumo de SPA.

Em 1839, a Inglaterra, em guerra econômico-comercial com a China, para proteger o seu tráfico de ópio, impulsionou a primeira "guerra do ópio" (SEIBEL; TOSCANO JR., 2001). Nesse contexto, acontece uma expansão das políticas de controle, "primeiro do tráfico e depois do consumo de algumas substâncias consideradas como ilícitas a partir do século XX, em seguida algumas medidas se voltam contra os direitos dos consumidores, inclusive suprimindo seus direitos civis" (ROSA; GUIMARÃES, 2017, p. 214).

Por sua vez, MacRae (2016) analisa a articulação entre canabis e racismo, com base nas primeiras ações de constituição das políticas sobre drogas no país, sinalizando para seu uso político, no combate ao "fumo de 


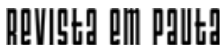

\} O RACISMO NA/DA POLÍTICA PROIBICIONISTA - ROSA, L. C. S.; GUIMARÃES, T. A. A. \}

DOI: $10.12957 /$ REP.2020.47204

Angola" - uma clara alusão ao consumo estigmatizado da maconha entre parte dos segmentos negros. O autor mostra que as primeiras ações políticas sobre drogas no Brasil, nos anos 1920, tinham relação imbricada com ações eugenistas, higienistas e racistas, postas em ação pelas elites, na perspectiva de "assegurar a manutenção das antigas estruturas sociais". Ao mesmo tempo, "apontava um meio de perseguir, encarcerar e excluir as populações pobres do País, não por acaso, em sua grande maioria, negros e pardos" (VALLADARES, 1991, p. 36), crescentemente incluídas no rol das "classes perigosas".

As ações tinham caráter explicitamente classista e racista, haja vista que, no mesmo período, no Rio de Janeiro, a cocaína era comprada em farmácia, ou seja, legalizada. Seu uso era considerado um "vício elegante" (SAAD, 2013), pois era consumida majoritariamente por pessoas da elite branca. De outra maneira, o consumo da maconha, também conhecida como "ópio do pobre" e "fumo de Angola", era criminalizado por ser considerado um vício.

A partir disso, por meio do Decreto $\mathrm{n}^{\circ} 14.969 / 21$, o dependente passa a ser remetido para tratamento compulsório em "sanatório para toxicômano". Em suma, o consumidor, sobretudo o dependente, era tratado no binômio repressão-assistência. Nessa perspectiva, os profissionais da saúde difundem a mesma visão de mundo do universo criminológico brasileiro, contribuindo para construir a opinião pública do período e também para influenciar as ações governamentais, por meio da Liga Brasileira de Higiene Mental, criada em 1923, referendando que "o Brasil se degradava moral e socialmente, por causa dos vícios, da ociosidade e da miscigenação racial do povo brasileiro" (COSTA, 1980, p. 17).

MacRae (2016, p. 26) afirma que, em 1932, a maconha foi incorporada à relação de "entorpecentes de venda proibida", que contou com a força midiática, associando a figura do consumidor de maconha ao "vagabundo e arruaceiro", abrangendo inclusive os praticantes da capoeira e os sambistas. Esse fato remete totalmente aos segmentos negros, de baixa renda, e passa a justificar ações arbitrárias, violentas e racistas pela polícia, desconsiderando o peso cultural que o consumo da maconha tinha entre parte desses segmentos, inclusive no rol da resistência cultural.

Isso ocorre em sintonia com a apropriação médica na tradução do consumo como "doença". Houve ação intensa dos médicos no período, que passam a influenciar o desenho das políticas proibicionistas consolidadas entre as décadas de 1920 e 1930, em diálogo e articulação com o meio jurídico, configurando um sistema médico-judicial que endossou as políticas racistas. Desse modo, a criminalização do consumo da maconha esteve intimamente relacionada ao preconceito racial, com intensa criminalização das práticas culturais africanas.

O processo de criminalização estava acompanhado de um "discurso salvacionista", na direção de disciplinar o modo de vida desses segmentos, sobretudo através da internação dos "toxicômanos" e de prisão dos "trafi- 


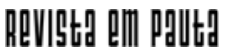

\} O RACISMO NA/DA POLÍTICA PROIBICIONISTA - ROSA, L. C. S.; GUIMARÃES, T. A. A. \}

DOI: $10.12957 /$ REP.2020.47204

cantes". Existia parca e difícil distinção legal entre um e outro, o que persiste como uma marca de toda política sobre drogas brasileiras.

Sob a influência das políticas norte-americanas, na perspectiva de orientar a formatação de políticas sobre "drogas" de outros países, passase a difundir maior controle e repressão internacional de fabricação, circulação e consumo de SPA. Dessa forma, estabelece-se uma política proibicionista, concebida como: "um modelo político-repressivo altamente segregacionista e moralista" (TAFFARELLO, 2009, p.143), em que os Estados passam a "ter papel fundamental em classificar um conjunto de substâncias tornadas ilícitas" (FIORE, 2012, p. 9).

Ganha realce a ação sobre três produtos em particular: a papoula/ ópio/heroína; a coca/cocaína e a cannabis/maconha. Essas ações influenciaram o entendimento contemporâneo em relação às SPAs, estabelecido a partir de limites arbitrários que definiram os produtos permitidos em contraposição aos ilegais, fundamentado em duas premissas: (1) que o uso desses produtos é danoso e, portanto, deve ser proibido; (2) que a ação do Estado deve se orientar para punir os produtores, vendedores e consumidores, criminalizando a circulação, na direção de uma "sociedade sem drogas".

Em síntese, o proibicionismo, segundo Teixeira et al. (2017), visa combater o tráfico e criminalizar os usuários. Está relacionado ao discurso antidrogas, resultado de tratados internacionais que tinham como objetivo a prevenção do consumo e a repressão da produção e da oferta. Centra a ação na substância, como se a "droga" fosse um mal em si mesma, ao que os teóricos críticos denominam "demonização da substância", haja vista ser um produto inerte. Tem sentido apenas a partir da relação que o ser humano estabelece com este, em determinado contexto, a partir de distintas funções e significados. Assim, moralizam-se condutas e criminaliza-se o consumidor de substâncias, considerado com "falta de caráter", alguém que "não tem jeito", "alguém do mal", um risco para a sociedade, um subcidadão, um não cidadão. Como discute Valois (2019, p. 20),

guerra às drogas é sinônimo da criminalização arbitrária de certas relações que o ser humano trava com algumas substâncias, mas drogas não morrem $[\ldots]$ aos poucos, o termo guerra às drogas vem revelando a sua face exclusivamente desumana de uma guerra contra as pessoas.

Porém, essas pessoas são situadas em determinada posição social, haja vista que "quanto mais negro, quanto mais pobre, mais ameaçadas a vida, a privacidade e a liberdade" (VALOIS, 2019, p. 13). Carl Hart (2014), um neurocientista americano, mostra a conexão entre a política proibicionista americana e a criminalização dos negros naquela sociedade, fato que se reproduziu no Brasil.

Medina, Nery Filho e Flach (2014) sinalizam como principais leis a partir de 1930: o Decreto ${ }^{\circ} 20.930$, de 1932, que destacou a posse de substâncias ilícitas como uma ação criminosa; o Decreto-Lei nº 891, de 


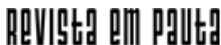

\} O RACISMO NA/DA POLÍTICA PROIBICIONISTA - ROSA, L. C. S.; GUIMARÃES, T. A. A. \}

DOI: $10.12957 /$ REP.2020.47204

1938, que associa o consumo com o crime, refletindo no Código Penal de 1940, que ratifica a criminalização do usuário; e a Lei n ${ }^{\circ} 11.343$, de 2006, que, pela primeira vez, buscou distinguir o usuário do traficante de drogas. Ao mesmo tempo em que tal marcador foi estabelecido e louvado, foi sinalizado como óbice ao exercício do direito, haja vista o fato de essa lei não estabelecer parâmetros quantitativos de drogas a serem considerados para distinguir um personagem do outro. Esse fato leva à subjetividade no critério de classificação, deixando a tarefa para o policial militar, que o juiz tende a validar (VALOIS, 2019).

O juiz tem de levar em conta "se a droga se destinava a consumo pessoal, a natureza e a quantidade da substância apreendida, o local e as condições em que se desenvolveu a ação, as circunstâncias sociais e pessoais, bem como a conduta e os antecedentes do agente" (BRASIL, 2006), o que varia de acordo com cada decisão. Abramovay (2017) aponta que a diferença entre usuários e traficantes é totalmente diluída na lei. Na ausência de critérios objetivos, prevalecem o racismo e o classismo, tão enraizados na sociedade brasileira.

Os dados revelam que brancos em regiões mais nobres das cidades são considerados usuários, mesmo com quantidades maiores de droga do que negros, que tendem a ser considerados traficantes. O critério se estabeleceu na prática: Se é 'branco é usuário, negro é traficante'. (ABRAMOVAY, 2017, p. 47).

Como consequência disso, o Levantamento de informações penitenciárias (Infopen) (BRASIL, 2014) informa que houve um aumento de $200 \%$ da população carcerária relacionado ao consumo de drogas, com predomínio de jovens, negros e sem antecedentes criminais. Logo, o aparato estatal repressivo-assistencial, que opera a partir de distinções equivocadas em relação ao usuário e ao traficante, é seletivo (BOITEUX, 2015), de modo que o Brasil é o terceiro país que mais encarcera no mundo. Desde a aprovação da Lei $\mathrm{n}^{\circ}$ 11.343, de 2006, que trata da questão das drogas, há mais de 700 mil pessoas presas, das quais $64 \%$ se declararam negras.

Especialistas da área criticam o proibicionismo por entender que não se pode criminalizar um comportamento que não produz danos a bens jurídicos de terceiros. Karam (2013, p. 33-34) ratifica esta ideia quando afirma que "[...] essa proibição globalmente imposta trouxe uma ilegítima intromissão do Estado na liberdade individual e uma desastrada intervenção do sistema penal sobre o mercado produtor e distribuidor [...]". Nesse sentido, pode-se dizer que há um atentado contra os direitos fundamentais.

Corroborando com esse pensamento, Lima (2012) considera o paradigma proibicionista como criminalizador da pobreza por ser um caminho seletivo, em que se atingem as classes sociais desfavorecidas economicamente, além de fazer um recorte étnico e racial. Portanto, indica que o Estado abre mão do seu papel provedor de bem-estar social e passa a ter cará- 


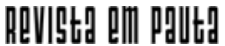

\} O RACISMO NA/DA POLÍTICA PROIBICIONISTA - ROSA, L. C. S.; GUIMARÃES, T. A. A. \}

DOI: $10.12957 /$ REP.2020.47204

ter punitivo. Diante disso, a repressão às drogas como ação prioritária de combate ao consumo tem contribuído para sustentar a rede de corrupção, tráfico de armas e lavagem de dinheiro, que repercutem negativamente no cotidiano das pessoas. Por outo lado, gera tratamento desigual entre consumidores de drogas lícitas e ilícitas, bem como discricionariedade da ação policial, recaindo nas periferias, nos pobres e nos negros. São erros estratégicos - de uma política calcada no proibicionismo - que servem a interesses econômicos e políticos de dominação e opressão, legitimando a violência e a criminalidade violadora de direitos. Além disso, ocultam as determinações sociais que incidem no padrão de consumo dos psicoativos (BRITES, 2017).

Vale frisar que a coação às drogas, nas zonas periféricas, é realizada sem obediência aos aspectos legais com respeito à privacidade, conforme preconizado pela Constituição Federal. Ao contrário do que ocorre nas áreas mais nobres, só o estigma racista legitima a aplicação de uma intervenção que mira a arma para a zona menos provida da cidade.

\section{Redução de danos como antídoto antirracista}

A redução de danos (RD) se baseia nos direitos humanos e nos princípios do pragmatismo e do humanismo, objetivos imediatos e atingíveis, partindo do reconhecimento de que as drogas podem ser prejudiciais, mas fazem parte da sociedade (MARLATT; WITKIEWITZ, 2010). Suas origens remetem a uma lógica participativa, pois situam o sujeito como autorregulador e corresponsável pelo seu processo de cuidado. Faz-se, assim, uma intervenção no seu território de vida, a partir de suas possibilidades e perspectivas, tendo por foco a defesa da vida e da liberdade e indo de encontro ao moralismo.

A RD como intervenção voltada ao consumo de substâncias psicoativas surge em 1926, na Inglaterra, por causa da autorização legal dada aos médicos para prescrever opiáceos aos consumidores. Posteriormente, nos anos 1980, na Holanda, em razão dos elevados índices de hepatite B, HIV/Aids, essa proposta foi configurada em forma de programas, obtendo como prática mais conhecida a troca de seringas usadas por novas, com usuários de drogas injetáveis.

No Brasil, no início da década de 1980, foi implantado institucionalmente o Conselho Federal de Entorpecentes (Confen), que defendia a primazia de ações relacionadas à prevenção sobre as ações curativas e repressivas (MEDINA; NERY FILHO; FLACH, 2014). Esse período é marcado pela epidemia da Aids, com o alerta dos elevados índices de pessoas infectadas em razão do consumo compartilhado de seringas entre usuários de drogas injetáveis, acarretando críticas ao modelo proibicionista.

Nessa perspectiva, em 1989, alguns profissionais de saúde na cidade de Santos iniciam outras estratégias, baseadas em ações socioeducativas 


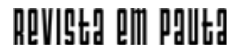

\} O RACISMO NA/DA POLÍTICA PROIBICIONISTA - ROSA, L. C. S.; GUIMARÃES, T. A. A. \}

DOI: $10.12957 /$ REP.2020.47204

e em uma atenção mais humanizada aos usuários. Essas ações foram ancoradas em programas de redução de danos e conceituadas como aquelas que "estimulam os indivíduos com comportamento excessivo ou de alto risco a dar um passo de cada vez para reduzir as consequências prejudiciais de seu comportamento" (MARLATT, 1999, p. 47). Iniciaram-se, assim, como atividades de trocas de seringas, mas que não se prolongaram devido a ações judiciais, que trataram os profissionais como "traficantes" ou fomentadores do uso.

Essas experiências inspiraram, em 1995, profissionais de saúde e pesquisadores da Universidade Federal da Bahia (Cetad/Ufba) a criarem o primeiro programa de troca de seringas no Brasil, possibilitando a construção de ações embrionárias de atenção nas cenas de uso dos próprios consumidores de SPA. Culminaram nos consultórios de rua, baseados na perspectiva da redução de danos (BASTOS; MESQUITA, 2001).

Porém, diante dos desafios impostos pela Aids, o governo se abre para outras lógicas de compreensão e abordagem do consumo e dos consumidores de SPA, cedendo espaço para uma perspectiva orientada pelos direitos humanos. Nesse paradigma, as pessoas que usam drogas são vistas como autônomas e capazes de tomar suas próprias decisões, de acessar políticas públicas sem ter que superar barreiras desnecessárias, incluindo regulamentações onerosas e discriminatórias. Compreende-se como clínica no cuidado de pessoas usuárias de produtos psicoativos, de baixa exigência, pois não preconiza a abstinência como pré-condição para o cuidado. Voltase para a redução de eventuais danos causados pelo produto, por sua via de administração, condições ambientais de uso, compartilhamento de equipamentos para o uso, bem como estado de higiene e nutricional do usuário.

É importante destacar que a RD não se contrapõe à abstinência. A interrupção do uso pode ser ou não o fim, pois essa abordagem engloba todas as opções de vontades, prevalecendo o cuidado e o respeito à singularidade de cada sujeito. Parte do pressuposto de que o Estado, através das políticas sociais, deve assistir o usuário em qualquer condição. Para Nery Filho (2019, p. 5), a RD está relacionada tanto às questões individuais e comunitárias quanto políticas e legais, "devendo repercutir não somente sobre as percepções sociais ampliando os conhecimentos e flexibilizando atitudes e comportamentos, mas também sobre os aspectos jurídicos e legislativos que incidem fortemente sobre estas percepções". Ressalta, ainda, que muitos dos danos provocados pelo consumo de SPA são frutos da estigmatização social, racismo e pobreza que reverberam na capacidade de os indivíduos reduzirem suas vulnerabilidades.

O olhar sobre a substância é ampliado para identificar as vulnerabilidades sociais. Assim, outros espaços de atuação são dinamizados, "as cenas de uso". Os profissionais se transportam para os locais onde os usuários estão, possibilitando maior acesso a serviços de saúde e cuidados em geral, diversificando o repertório de intervenções das políticas públicas. 


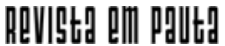

\} O RACISMO NA/DA POLÍTICA PROIBICIONISTA - ROSA, L. C. S.; GUIMARÃES, T. A. A.

DOI: $10.12957 /$ REP.2020.47204

A partir de 1997, são criados os movimentos no campo das políticas sobre drogas: a Associação Brasileira de Redutores de Danos (Aborda), a Rede Brasileira de Redução de Danos (Reduc) e a Rede Latino-Americana de Redução de Danos (Relard). Neste período, observa-se que a categoria de redutores de danos inicia as ações territoriais diretas junto aos usuários de drogas (DOMANICO; MACRAE, 2006).

Os anos 2000 são considerados como o período de maior produção de leis e reorientações das políticas sobre drogas no país, tendo destaque: a Portaria n ${ }^{\circ} 336 / 2002$, de implantação dos Centros de Atenção Psicossocial (Caps), incluindo a modalidade álcool e drogas; a Portaria $n^{\circ} 816$, que institui o Programa Nacional de Atenção Comunitária Integrada a Usuários de Álcool e Outras Drogas e explicita os fundamentos da lógica da redução de danos; a Portaria Ministerial no 1.612/05, que redireciona a atenção da internação em hospitais psiquiátricos para os hospitais gerais, ou seja, um cuidado na perspectiva desmanicomializante; e o Plano Emergencial de Ampliação do Acesso ao Tratamento e Prevenção em Álcool e outras Drogas no SUS (Pead), que visou ampliar o acesso ao tratamento e à prevenção no SUS, diversificar as ações de prevenção, promover a saúde, tratar e reduzir riscos e danos, além de construir respostas intersetoriais efetivas, sensíveis ao ambiente cultural, aos direitos humanos e à complexidade desta clínica.

Ao mesmo tempo, há investimento em pesquisas epidemiológicas de abrangência nacional, tais como os levantamentos domiciliares sobre o uso de drogas psicotrópicas no Brasil, que permitiram conhecer o perfil do consumo de SPA, coordenado pelo Centro Brasileiro de Informações sobre Drogas Psicotrópicas (Cebrid). Concomitantemente, na arena governamental, assiste-se ao direcionamento distinto das políticas sobre drogas, tendo em vista a Secretaria Nacional Antidrogas, explicitamente voltada para a perspectiva proibicionista, de origem norte-americana. Por outro lado, se posiciona o Ministério da Saúde, que assume o consumo prejudicial como uma questão de saúde pública, alinhada aos princípios da redução de danos (MOTA et al., 2012).

Tais fatos indicam as contradições do Estado brasileiro; ao tempo em que sinaliza para a perspectiva de Estado ampliado, em que há espaço para as necessidades da sociedade civil, paulatinamente forja um realinhamento entre as ações do Ministério da Justiça e da Saúde na direção da redução de danos, apesar da persistência da hegemonia da lógica proibicionista.

A partir de 2010, o governo federal passa a ampliar seu escopo de atuação com foco na RD. São criados os consultórios de/na rua, proporcionando maior permeabilidade e sensibilidade das ações para públicos distintos, sobretudo população negra; portanto, voltadas para a equidade racial. Outro marco importante foi a instituição do Plano Crack, através do Decreto $\mathrm{n}^{\circ} 7.179$, em resposta a uma suposta epidemia de crack, forjada por meio da mídia. Além disso, há também a implantação da Rede de Atenção 


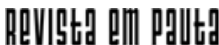

\} O RACISMO NA/DA POLÍTICA PROIBICIONISTA - ROSA, L. C. S.; GUIMARÃES, T. A. A. \}

DOI: $10.12957 /$ REP.2020.47204

Psicossocial (Raps), que caracteriza os componentes e a missão na atenção ao consumidor de SPA, ativando a potência de outros equipamentos, para além do Caps-AD, num reforço a outro olhar e numa ação intra e intersetorial. Há uma diversificação de equipamentos, serviços e estratégias que acompanham e contemplam a pluralidade de identidades e necessidades dos consumidores de SPA, observando-se, assim, maior capilarização da atenção e da abordagem.

Em 2014, foi publicada a Pesquisa nacional sobre o uso de crack: quem são os usuários de crack e/ou similares do Brasil, coordenada pela Fiocruz/Rio de Janeiro (BASTOS; BERTONI, 2014), que desconstrói a ideia de que haveria uma epidemia de crack no país. A Política Nacional de Saúde Integral da População Negra (BRASIL, 2007) igualmente sinaliza o diagnóstico da situação de saúde de que parte significativa de consumidores de SPA é negra. Da mesma forma, a Política Nacional de Saúde do Homem (BRASIL, 2008) mostra como a violência, sobretudo os homicídios, coloca os negros, especialmente os jovens, tanto como principal vítima quanto perpetradores, até pela influência da masculinidade hegemônica.

Parte do movimento negro tem se articulado com a luta antiproibicionista, na perspectiva de apresentar proposições para inverter esse quadro. Isso porque "pessoas usuárias de drogas em extrema vulnerabilidade não possuem como fonte desorganizadora o uso abusivo da substância, e sim a exposição à violência ou a ausência de direitos mínimos, como renda, alimentação e moradia" (OLIVEIRA; RIBEIRO, 2018, p. 39).

Nesse contexto, a implementação do paradigma da redução de danos, associada a toda uma conjuntura política favorável aos direitos humanos e avanços das forças democráticas, evidenciou as particularidades de segmentos até então invisíveis nas políticas sobre drogas, bem como suas vulnerabilidades associadas a marcadores que expressam acúmulos de desvantagens sociais. O destaque recai sobre a condição de homens e mulheres negras no país, bem como a condição do segmento lésbicas, gays, bissexuais, travestis, transexuais e pessoas intersex (LGBTQI+), criando-se estratégias de cuidado baseadas na equidade, principalmente racial, que busca inverter a tendência de homogeneização dos consumidores.

Como visto acima, a RD tem uma forte marca antirracista. Portanto, é um antidoto à lógica proibicionista, o que explica, em parte, a aversão a seus avanços e fundamentos. Ademais, vale lembrar que $74 \%$ dos usuários do SUS se declaram pardos ou negros (DAVID; MARQUES; SILVA, 2019), o que imprime uma dimensão ética e política à sua defesa.

Todo o edifício da RD encontra-se em processo de desmoronamento pelo fortalecimento das forças conservadoras, que intensificam o redirecionamento da política de drogas no país, com maior velocidade a partir de 2016 e sobretudo com o Presidente Bolsonaro, que altera a Política Nacional de Saúde Mental (PNSM) sob a égide da Reforma Psiquiátrica (GUIMARÃES; ROSA, 2019). Neste contexto, as comunidades terapêuticas (CTs) 


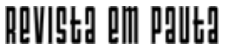

\} O RACISMO NA/DA POLÍTICA PROIBICIONISTA - ROSA, L. C. S.; GUIMARÃES, T. A. A. \}

DOI: $10.12957 /$ REP.2020.47204

foram regulamentadas através da Resolução no 1, de 19 de agosto de 2015, e reafirmadas como estabelecimentos de saúde por meio da Portaria SAS/ MS n.1.482, de 25 de outubro de 2016, capacitando-as a receberem recursos do SUS, na contramão dos avanços da Reforma Psiquiátrica no Brasil e da redução de danos. Cabe ressaltar que há remanicomialização dos cuidados e fomento ao ente privado no interior do SUS, com intensa precarização da Raps.

Em 2019, é criada a Secretaria Nacional de Cuidados e Prevenção às Drogas, ligada ao Ministério da Cidadania, estabelecendo uma "nova" política nacional sobre drogas por meio do Decreto ํo 9.761, de 11 de abril de 2019. Esta se ancora em um viés proibicionista, com tratamento em comunidades terapêuticas, focada em abstinência, cuja posição é majoritariamente contrária às iniciativas de legalização de drogas. Revoga-se o Decreto $n$. 4.345 , de 26 de agosto de 2002, o qual fundamentava juridicamente a política que reconhecia a redução de danos como intervenção preventiva de base. Tais alterações sinalizam para o retorno e reforço de uma política racista, em que a vida dos negros figura como de menor valor.

Desse modo, concordando com Nery Filho (2019, p. 7), a redução de danos não se cria ou se destitui em uma "canetada", por decretos ou portarias. Ela é uma necessidade que "transforma pessoas, cuidadores, a partir dos 'bons encontros', no reconhecimento recíproco e na honestidade das diferenças e das diferentes escolhas que cada um(a) pode fazer em suas vidas", sendo constitutivamente uma política multicultural/antirracista.

\section{Considerações finais}

A política proibicionista se traveste de uma política racista, por associar o crime, as drogas e a violência às dimensões étnicas e raciais, que impulsionam o encarceramento de negros. Logo, as injustiças e a exclusão social conjugam-se à violação de direitos que estruturam o poder e acirram a marginalização de pessoas por suas condições de miséria e vulnerabilidade. Ademais, atua como ferramenta de manutenção da segregação racial e da atuação seletiva das instituições judiciais e de segurança, pois mantém negros e pobres oprimidos e estigmatizados.

A conjuntura exige resistência das lutas antiproibicionistas para a materialização de direitos humanos, por meio de intervenções integrativas e inclusivas que operem como mecanismo legítimo de defesa da vida e de promoção da saúde do indivíduo e da coletividade. Por fim, lutar pela RD e pelo SUS é atuar em prol de ações antirracistas. 


\section{ReVIStg a d P p putt}

\} O RACISMO NA/DA POLÍTICA PROIBICIONISTA - ROSA, L. C. S.; GUIMARÃES, T. A. A. \}

DOI: $10.12957 /$ REP.2020.47204

\section{Referências}

ABRAMOVAY, P. Branco é usuário, negro é traficante. PISEAGRAMA, Belo Horizonte, n. 11, 2017.

ANTUNES, R. Adeus ao trabalho? Ensaio sobre as metamorfoses e a centralidade do mundo do trabalho. São Paulo: Cortez, 1998.

BARATA, R. B. Como e por que as desigualdades sociais fazem mal à saúde. Rio de Janeiro: Fiocruz, 2009.

BASTOS, F. I.; BERTONI, N. Pesquisa nacional sobre o uso de crack: quem são os usuários de crack e/ou similares do Brasil? Quantos são nas capitais brasileiras? Rio de Janeiro: ICICT/Fiocruz, 2014.

BASTOS F. I.; MESQUITA, F. Estratégias de redução de danos. In: SEIBEL, S. D.; TOSCANO JR., A. Dependência de drogas. São Paulo: Atheneu, 2001.

BOITEUX, L. El antimodelo brasileño: prohibicionismo, encarcelamiento y selectividad penal frente al tráfico de drogas. Nueva Sociedad, v. 255, 2015.

BRASIL. Lei n. 11.343, de 23 de agosto de 2006. Institui o Sistema Nacional de Políticas Públicas sobre Drogas - Sisnad; prescreve medidas para prevenção do uso indevido, atenção e reinserção social de usuários e dependentes de drogas; estabelece normas para repressão à produção não autorizada e ao tráfico ilícito de drogas; define crimes e dá outras providências. Diário Oficial da União. Brasília, 24 ago. 2006. Disponível em: http:// pesquisa.in.gov.br/imprensa/jsp/visualiza/index.jsp?data=24/08/2006\&jornal $=1$ \&pagina $=2$ \&totalArquivos=200. Acesso em: 19 jun. 2019 .

BRASIL. Política nacional de saúde integral da população negra. Brasília: Secretaria Especial de Políticas de Promoção da Igualdade Racial, 2007.

BRASIL. Política nacional de atenção integral à saúde do homem: princípios e diretrizes. Brasília, DF: Ministério da Saúde, 2008.

BRASIL. Ministério da Justiça. Levantamento nacional de informações penitenciárias. 2014. Disponível em: http://www.justica.gov.br/noticias/mjdivulgara-novo-relatorio-do-infopen-nesta-terca-feira/relatorio-depen-versaoweb.pdf. Acesso em: 19 jun. 2019.

BRITES, C. M. Consumo de psicoativos, proibicionismo e ética profissional das(os) assistentes sociais. In: DUARTE, M. J. O.; PASSOS, R. G.; GOMES, T. M. S. (org.). Serviço Social, saúde mental e drogas. Campinas: Papel Social, 2017.

CONCEIÇÃO, A. C.; NERY, G. C.; PINHO, S. R. Rubim de Pinho: fragmentos da psiquiatria transcultural. Salvador: Universidade Federal da Bahia, 2002.

COSTA, J. F. História da psiquiatria no Brasil. Rio de Janeiro: Campus, 1980.

COSTA, J. F. Ordem médica e norma familiar. Rio de Janeiro: Graal, 1983. 


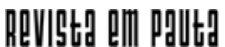

\} O RACISMO NA/DA POLÍTICA PROIBICIONISTA - ROSA, L. C. S.; GUIMARÃES, T. A. A. \}

DOI: $10.12957 /$ REP.2020.47204

DAVID, E. C.; MARQUES, A. L. M.; SILVA, F. F. L. Redução de danos e racismo. In: SURJUS, L. T. L. S.; SILVA, P. C. (org.). Redução de danos: ampliação da vida e materialização de direitos. Santos: Unifesp, 2019.

DOMANICO A.; MACRAE, E. Estratégias de redução de danos entre usuários de crack. In: SILVEIRA, D. X.; MOREIRA, F. G. Panorama atual de drogas e dependências. São Paulo: Atheneu, 2006.

DRAIBE, S. As políticas sociais brasileiras: diagnósticos e perspectivas. In: IPEA/IPLAN. Prioridades e perspectivas de políticas públicas. Brasília: Ipea/ Iplan, 1989.

FAUSTINO, D. M. A equidade racial nas políticas de saúde. In: BATISTA, L. E.; WERNECK, J.; LOPES, F. (org.). Saúde da população negra. Petrópolis: DP, 2012.

FIORE, M. O lugar do Estado na questão das drogas: o paradigma proibicionista e as alternativas. In: CEBRAP. Novos estudos. São Paulo: Cebrap, 2012.

FREIRE, P. Pedagogia da autonomia. São Paulo: Paz e Terra, 1996.

GUIMARÃES, T. A. A.; ROSA, L. C. S. A remanicomialização do cuidado em saúde mental no Brasil no período de 2010-2019: análise de uma conjuntura antirreformista. O Social em Questão, Rio de Janeiro, ano XXII, v. 1, n. 44, maio/ago. 2019. Disponível em: http://osocialemquestao.ser.puc-rio.br/ media/OSQ_44_art5.pdf. Acesso em: 10 jun. 2019.

HART, C. Um preço muito alto: a jornada de um neurocientista que desafia nossa visão sobre as drogas. Rio de Janeiro: Zahar, 2014.

HENMAN, A. A guerra às drogas é uma guerra etnocida. In: ZALUAR, A. (org.). Cidadania e repressão ou redução de riscos. Rio de Janeiro: Brasiliense, 2016.

IAMAMOTO, M. V.; CARVALHO, R. Relações sociais e Serviço Social no Brasil: esboço de uma interpretação histórico-metodológica. São Paulo: Cortez, 2011.

KARAM, M. L. Direitos humanos, laço social e drogas: por uma política solidária com o sofrimento humano. In: CFP. Drogas, direitos humanos e laço social. Brasília: CFP, 2013.

LEAL, V. N. Coronelismo, enxada e voto: o município e o regime representativo no Brasil. São Paulo: Companhia das Letras, 2012.

LIMA, R. C. C. O proibicionismo às drogas: sua periodização e seus marcos transnacionais. In: GARCIA, M. L. T. G.; LEAL, F. X. L. (org.). Análise de políticas públicas: temas, agenda, processos e produtos. São Paulo: Annablume, 2012. 


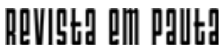

\} O RACISMO NA/DA POLÍTICA PROIBICIONISTA - ROSA, L. C. S.; GUIMARÃES, T. A. A. \}

DOI: $10.12957 /$ REP.2020.47204

MACRAE, E. Canabis, racismo, resistência cultural e espiritualidade. In: MACRAE, E.; ALVES, W. C. Fumo de Angola: canabis, racismo, resistência cultural e espiritualidade. Salvador: Edufba, 2016.

MARLLATT, G. A. Redução de danos: estratégias para lidar com comportamentos de alto risco. Porto Alegre: Artmed, 1999.

MARLATT, G. A.; WITKIEWITZ, K. Update on harm-reduction policy and intervention research. Annual Review of Clinical Psychology, v. 6, 2010.

MARX, K.; ENGELS, F. A ideologia alemã. São Paulo: Martins Fontes, 2001.

MEDINA, M. G.; NERY FILHO, A.; VON FLACH, P. M. Políticas de prevenção e cuidado ao usuário de substâncias psicoativas. In: PAIM, J. S.; ALMEIDAFILHO, N. (org.). Saúde coletiva: teoria e prática. Rio de Janeiro: MedBooks, 2014.

MONSMA, K. Racialização, racismo e mudança: um ensaio teórico, com exemplos do pós-abolição paulista. In: SIMPÓSIO NACIONAL DE HISTÓRIA, 17., Natal, jul. 2013.

MOTA, D. B. et al. Construindo a continuidade do cuidado ao usuário de álcool e outras drogas: alguns conceitos e questões para o trabalho em rede no Brasil. In: NERY FILHO, A.; MACRAE, E.; TAVARES, L. A.; RÊGO, M.; NUÑEZ, M. E. (org.). As drogas na contemporaneidade: perspectivas clínicas e culturais. Salvador: Edufba, 2012.

NERY FILHO, A. Por que os humanos usam drogas? In: NERY FILHO, A.; MACRAE, E.; TAVARES, L. A.; RÊGO, M.; NUÑEZ, M. E. (org.). As drogas na contemporaneidade: perspectivas clínicas e culturais. Salvador: Edufba, 2012.

NERY FILHO, A. Prefácio. In:SURJUS, L. T. L. S.; SILVA, P. C. (org.). Redução de danos: ampliação da vida e materialização de direitos. Santos: Unifesp, 2019. Disponível em: https://www.unifesp.br/campus/san7/images/E-bookReducao-Danos-versao-final.pdf. Acesso em: 3 jul. 2019.

OLIVEIRA, N.; RIBEIRO, E. O massacre negro brasileiro na guerra às drogas. SUR 28, v. 15, n. 28, 2018.

RESENDE, H. Política de saúde mental no Brasil: uma visão histórica. In: TUNDIS, S.; COSTA, N. Cidadania e loucura - políticas de saúde mental no Brasil. Petrópolis: Vozes, 1990.

ROSA, L. C. S.; GUIMARÃES, T. A. A. Repercussões nefastas da política proibicionista na imagem social do consumidor de substância psicoativa. In: LAURENTINO et al. (org.). A política de saúde mental no Piauí sob a égide da Raps. Teresina: EDUFPI, 2017.

SAAD, L. G. Fumo de negro: a criminalização da maconha no Brasil. Dissertação (Mestrado em História) - Programa de Pós-Graduação em História, UFBA, Salvador, 2013. No prelo. 


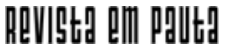

\} O RACISMO NA/DA POLÍTICA PROIBICIONISTA - ROSA, L. C. S.; GUIMARÃES, T. A. A. \}

DOI: $10.12957 /$ REP.2020.47204

SANTOS, R. E. Sobre espacialidade das relações raciais: raça, racialidade e racismo no espaço urbano. SANTOS, R. E. (org.). Questões urbanas e racismo. Brasília, DF: ABPN, 2012.

SANTOS, W. G. Cidadania e justiça: a política social na ordem brasileira. Rio de Janeiro: Campus, 1987.

SEIBEL, S. D.; TOSCANO JR., A. Dependência de drogas. São Paulo: Atheneu, 2001.

TAFFARELLO, R. F. Drogas: falência do proibicionismo e alterativas de política criminal. Dissertação (Mestrado em Direito) - Programa de Pós-Graduação em Direito, USP, São Paulo, 2009. No prelo.

TEIXEIRA, M. B. et al. Tensões paradigmáticas nas políticas públicas sobre drogas: análise da legislação brasileira no período de 2000 a 2016. Ciênc. Saúde Coletiva, Rio de Janeiro, v. 22, n. 5, maio 2017.

TELLES, V. Direitos sociais: afinal do que se trata? Belo Horizonte: UFMG, 1999.

VALLADARES, L. P. Cem anos pensando a pobreza (urbana) no Brasil. In: BOSCHI, R. R. (org.). Corporativismo e desigualdade: a construção do espaço público no Brasil. Rio de Janeiro: Iuperj/Rio Fundo, 1991.

VALOIS, L. C. O direito penal da guerra às drogas. Belo Horizonte: D'Plácido, 2019.

VIANA, L. W. Liberalismo e sindicato no Brasil. Rio de Janeiro: Paz e Terra, 1983.

DOI: $10.12957 /$ rep.2020.47204

Recebido em 05 de julho de 2019.

Aprovado para publicação em 31 de outubro de 2019.

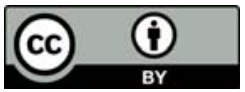

A Revista Em Pauta: Teoria Social e Realidade Contemporânea está licenciada com uma Licença Creative Commons Atribuição 4.0 Internacional. 